\title{
Multi-Objective Service Restoration of Distribution Systems Using User-Centered Methodology
}

\author{
Shuo Wang, and Hsiao-Dong Chiang, Fellow, IEEE
}

\begin{abstract}
A multi-objective problem formulation of service restoration and a three-stage methodology tailored to user-centered service restoration for large-scale, unbalanced distribution systems are presented. One feature is that it allows the experience and engineering judgment of users to be integrated into the three-stage methodology. Since solutions suggested by a method need to be compromised with engineering judgment, this methodology involves system users (at Stage II), meta-heuristics (at Stage I) and local heuristics in combination with restoration strategies (at Stage III) for efficient and robust performance in service restoration. An adaptive K-means method is incorporated in the proposed group-based PSO (Stage I) for global search. It also assists users in their decision making. The evaluation results of the proposed user-centered methodology on the IEEE 123-node test feeder and a 1011-node practical unbalanced network show its effectiveness and flexibility in restoring service after faults on these two test systems.
\end{abstract}

Index Terms -Adaptive K-means method, group-based particle swarm optimization, user-centered service restoration, diversified restoration scheme.

\section{INTRODUCTION}

$\mathrm{D}$ UE TO the ever-increasing demand for electric power, the size and complexity of the modern power distribution systems have increased significantly. This, in turn, has increased the likelihood of fault and overload events. Power system restoration after a major outage has always been an important issue to be addressed. When a fault occurs in a distribution system, a load transfer strategy to transfer the fault-free outage loads or overloads to other feeders must be made. However, it is a complicated and difficult task to determine effective load transfer strategies, as the fault types are diverse and the system loading condition changes. In particular, under heavy loading conditions, a multi-stage load transfer procedure is required to minimize the spreading effect of the events when it cannot be solved by only adjacent feeders [1-2].

Significant research has been devoted to solving the service restoration problem. References [3-5] propose heuristic-guided

Shuo Wang is with the School of Electrical Engineering and Automation, Tianjin University, Tianjin, 300072, China. (E-mail: nmsure@163.com).

Hsiao-Dong Chiang is with the School of Electrical and Computer Engineering at Cornell University, Ithaca, New York. (E-mail: chiang@ece.cornell.edu). reconfiguration methods to balance the load, relieve the overload, or minimize the fault-free outage load. Although these heuristic approaches generally provide a reasonable solution, they do not always guarantee a high-quality optimal solutions. Knowledge-based expert system techniques have been applied to provide guidelines for restoration in [6-7]. In general, these methods are very effective, but the structure of the expert system can be complex to be applied to practical systems. This problem has also been approached using the decomposition method [8], meta-heuristic algorithm [9-11], and fuzzy technology [12-13]. Other approaches for service restoration can be found in [14-17].

Service restoration may involve system operators, planners, protection staff and trainers, and there is a great need to develop a user-centered method that can offer multiple optimal solutions from which users may choose. To this end, we present a multi-objective problem formulation tailored to user-engaged service restoration and develop a user-centered methodology to integrate the following two goals: (i) restoring more customer loads with (ii) fewer switch operations. This methodology incorporates knowledge and preference from users with a group-based PSO and a local method to optimize the restoration process.

In this work, we take advantage of the global capability of a group-based PSO in Stage I to generate a set of "good" solutions located in several promising sub-regions in the search space. Stage II allows users to select preferred solutions for further improvement. Starting from each solution generated at Stage I, a local method in Stage III finds the corresponding local optimum. There are several distinguishing features in this work:

1. Engagement of users into decision-making: This user-centered methodology takes user preference into account. The users here refer to the operators in an electric utility. It is a crucial stage that affects the final service restoration scheme. An adaptive K-means clustering technique is applied in Stage I to assist users in their decision-making.

2. Diverse and high-performance solutions: A wide range of promising solutions are obtained and presented to users for flexibly injecting their preferences.

3. Efficient searching: Several proven heuristic rules have been incorporated into the proposed three-stage method 
to achieve efficient local search.

4. Large-scale network applications: This novel method is proposed to address the issue of PSO algorithms in solving large-scale optimization problems, such as extensive computation efforts (i.e., lengthy computation time) and lack of scalability. This methodology is applicable for large-scale distribution networks with thousands of switches.

The three-stage methodology has been applied to the IEEE 123-node test feeder and a practical 1011-node distribution network with promising results.

\section{PROBLEM FORMULATION}

\section{A. Objective Function}

In this work, the service restoration problem is formulated as a constrained multi-objective optimization problem. The aim of restoration is to restore as much power as possible and as quickly as possible, so the objective function goal is to find the fewest switch operations to restore the maximum amount of possible load:

$$
\begin{gathered}
\max _{g_{k} \in G_{R}} f_{1}=\sum_{k \in N_{R}}\left|\mathrm{P}_{L, k}\right| \\
\min _{g_{k} \in G_{R}} f_{2}=n_{\text {ops }}
\end{gathered}
$$

where $n_{\text {ops }}$ is the number of network switch operations to arrive at $g_{k}, g_{k}$ is the selected network configuration, $G_{R}$ is the set of possible radial configurations, $N_{R}$ is the set of restored buses, and $\mathrm{P}_{L, k}$ is the total active power injected to bus $k$.

\section{B. Constraints}

A feasible solution that satisfies all operational constraints is restricted by the multiphase unbalanced power flow equations. Branch current flows and feeder loading voltage magnitudes must lie within acceptable operating ranges. The preservation of a radial network structure must also be satisfied.

1) Topological restriction: A radial network structure is maintained;

2) Unbalanced power flow constraints are satisfied:

$$
f\left(V, g_{k}\right)=0
$$

3) Power source limit constraint:

$$
P_{l}^{2}+Q_{l}^{2} \leq\left(S_{l}^{\max }\right)^{2} \quad \forall l \in F
$$

4) Power quality: this can be referred to as voltage quality since harmonics and current quality are often not taken into account during restoration. Voltage magnitude is usually expressed as reasonable deviation in percentage from nominal voltage:

$$
V_{k}^{\min } \leq\left|V_{k}^{p}\right| \leq V_{k}^{\max } \quad \forall k \in N, p \in a, b, c
$$

5) Current constraint:

$$
\left|I_{i j}^{p}\right| \leq I_{i j}^{\max } \forall i j \in L
$$

where $V$ is the vector of node voltages; $F$ is set of all feeders; $S_{l}=\sqrt{P_{l}^{2}+Q_{l}^{2}}$ is the total apparent power entering feeder $l ; V_{k}^{p}$ is the voltage at $k$ bus; $I_{i j}^{p}$ is the current of line $i j$, phase $p ; L$ is the set of existing lines; and $N$ is the set of all buses.

\section{Solution MethodologIES}

A three-stage methodology is proposed to solve the user-centered service restoration problem, as shown in Fig. 1.

\section{Stage I: (global search)}

A group-based binary particle swarm optimization (BPSO) method is proposed for efficiently searching diversified near optimal solutions. The "group" represents a clustering scheme incorporated into the PSO iterations. This scheme provides a new criterion to judge whether all of the particles have reached a consensus and can adaptively terminate the iteration process when the algorithm converges. Based on the final clustering result, we then select the top particles in each cluster and output these solutions as candidate high-quality solutions in the following stage.

\section{Stage II: (user-engaged stage)}

From the solutions obtained in Stage I, a user-preferred

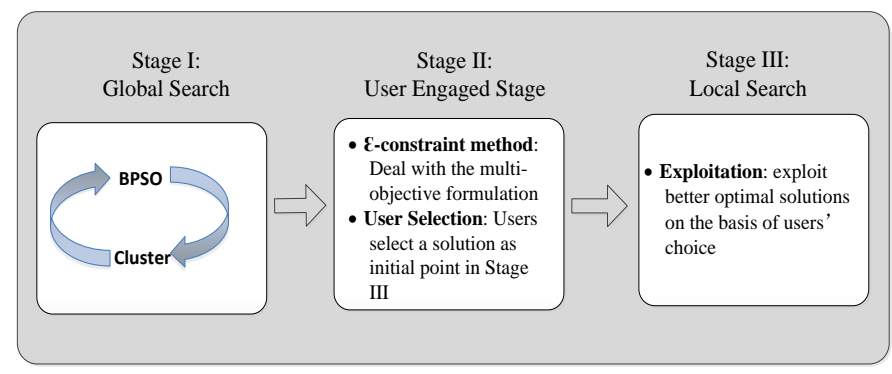

Fig 1. Overview of the three-stage methodology.

solution table is formed which is designed to engage operators in selecting one (or multiple) candidate solution. Based on the users' preferences in terms of the objectives, the original problem is then transformed into a single objective optimization problem by applying the $\varepsilon$-constrained method, which is designed to find the optimal solution is a non-inferior solution that satisfies users' expectations.

Stage III: (local and fine-tuning stage)

A combined local method and heuristic method is applied to solve the single-objective problem for the user-preferred solution.

Stage III can obtain multiple local optimal solutions. From all of the obtained solutions, the user can select the one that require the fewest switch operations to restore the maximum amount of possible load.

\section{A. Stage I: Global Stage}

The PSO algorithm exhibits fast converge during the initial stages, but since it lacks the local fine-tuning capability, this algorithm suffers from slow convergence in local searches. The proposed group-based PSO method takes advantage of the excellent capability of PSO to maintain the swarm diversity and avoids inefficient local searches by applying a new termination 
criterion. This new termination criterion replaces reaching maximum iterations with achieving a consensus state of all the particles. To be specific, all of the particles are clustered using an adaptive K-means clustering method [18] after every specific time iteration (i.e., every 20 times). Since the adaptive K-means method can adaptively determine the clustering number without being pre-defined, it helps the PSO finish the iteration as long as the particles have reached a consensus. The consensus state is justified by two conditions:

- The number of clusters is not changed;

- The cluster centers of two successive clustering procedures satisfy the following condition:

$$
C\left(x_{i}, x_{i+1}\right)=\left\|x_{i}-x_{i+1}\right\| \leq 0.1 * C\left(x_{i+1}, 0\right)
$$

where $x_{\mathrm{i}}$ and $x_{\mathrm{i}+1}$ represent the cluster center of $i$ th and $i+1$ th clustering, and $\mathrm{C}(X, Y)$ means the distance between point $X$ and $Y$. D is the length of decision variable $x$.

As discussed, a group-based PSO for constrained large-scale optimization problems consists of two steps:

Step I-1: (exploration and grouping) apply the group-based PSO to solve the constrained problem and terminate the iteration when all of the particles reach a consensus state.

Step I-2: (selection) based on the final clustering, select the top particles from each group, in terms of particle quality.

This scheme takes advantage of the excellent global search capability of PSO in locating multiple promising sub-regions for high-quality solutions. In this way, we don't aim for the final solution obtained by BPSO, but for the diversified near-optimal solutions instead.

To accelerate convergence and avoid generating a large number of unfeasible solutions, a repair strategy is adopted to remove violation of operation constraints. This strategy can 'repair' an unfeasible particle to make it feasible. The detailed description is introduced in section IV.

\section{B. Stage II: User-Engaged Stage}

This stage engages a user to select a preferable solution from the candidate ones obtained at Stage I for further improvements. For each solution, the user provides the following preference based on the objective function values of each selected solution:

(1). Select one of the objective functions as the primary objective function,

(2). Determine the tolerance value of each of the other m-1 objective functions.

The $\varepsilon$-constrained method is used to formulate the user preference with a single-objective optimization problem.

\section{$\varepsilon$-constrained method:}

We consider the following general multi-objective optimization (MO) problem.

$$
\begin{array}{ll}
\max & f_{1}(x) \\
\max & f_{2}(x) \\
\cdots & \\
\max & f_{m}(x)
\end{array}
$$

such that:

$$
\begin{aligned}
& F(x)=0 \\
& G(x) \leq 0
\end{aligned}
$$

where $\mathrm{x}$ is the vector of decision variables, and $f_{l}(x), \ldots, f_{m}(x)$ are the $m$ objective functions.

In the $\varepsilon$-constraint method, we optimize one of the objective functions using the other objective functions as constraints, incorporating them into the constraint part of the model, as shown below.

To be specific, suppose that $f_{i}$ is the primary objective function, and the method transforms the multiple objective functions into the following single objective optimization problem:

$$
\max f_{i}(\mathrm{x})
$$

such that

$$
\begin{aligned}
& f_{i}(x) \leq \varepsilon_{j}, j=1,2, \ldots, m ; j \neq i \\
& F(x)=0 \\
& G(x) \leq 0
\end{aligned}
$$

In service restoration problems, $\varepsilon_{2}>0$ is a tolerance value for the number of switch operations selected by operators, which means that we attempt to obtain a better result for $f_{l}$ at the expense of $f_{2}$. A systematic variation of $\varepsilon_{j}$ will generate different non-inferior solutions. For the service restoration problem, its value is selected by the user.

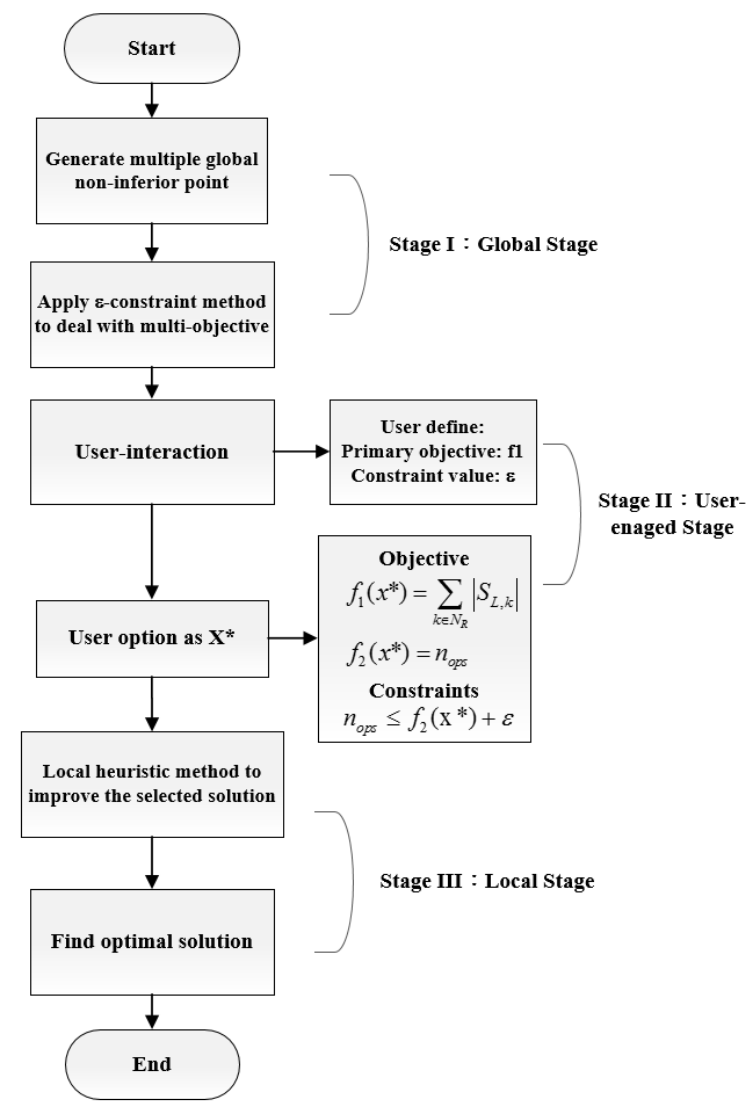

Fig. 2. Flowchart of the proposed three-stage method 


\section{Stage III: Local and Fine-Tuning Stage}

For the single objective optimization problem constructed in Stage II, a ranking-based switch search method is adopted to find the corresponding local optimal solutions satisfying user preference. This method is originally developed in [19-20]. However, it cannot guarantee an optimum solution. It is adapted in this paper for local fine-tuning in stage III, which is shown to generate more feasible optimal solutions than the original method. To this end, we develop three-switch selection indices, based on tie switches ( $t s)$ and sectionalizing switches $(s s)$ :

$\cdot Z_{\text {path }}$ : the electrical distance of each $t s$ to other buses;

$\cdot I_{s s}$ : the amount of load each ss can transfer to a $t s$;

$\cdot I_{M}$ : the spare capacity of each $t s$;

For each $t s, I_{M}$ is defined as the smallest margin in the path between a tie switch and the substation, which is expressed as follows:

$$
I_{M}=\min _{k \in N_{u}, p}\left(I_{k}^{\max }-\left|I_{k}^{p}\right|\right)
$$

where $N_{u}$ is the set of upstream buses on the path between a tie switch and the substation.

The electrical distance $Z_{\text {path }}$ is given by

$$
Z_{\text {path }}=V_{t s} / \sum_{k \in N_{v}} I_{L, k}
$$

where $N_{v}$ is the set of all buses lying in the path between the $t s$ and the bus with the voltage violation. $I_{s s}$ is defined as the amount of load that each sectionalizing switch can transfer to a tie switch. It is computed as the sum of all the loads down-stream from the sectionalizing switch:

$$
I_{s s}=\sum_{C_{d}} I_{L}
$$

where $C_{d}$ is the set of all buses lying downstream from the secondary side of the sectionalizing switch. The transferrable load is also used as an index to distinguish switch pairs to handle current flow and feeder capacity constraints.

In this stage, the above three indices are used to develop ranking-based switch search methods for finding optimal solutions as follows:

Step 3-1: Check the unrestored outage. Update the outage area.

Step 3-2: Build the candidate tie and sectionalizing switch list for Tier 1.

Step 3-3: Close the tie switch with the largest spare capacity nearest to the outage area to attempt full restoration of the out-of-service area. If unrestored loads still exist, go to the next step.

Step 3-4: Select and operate the candidate switch pairs for full restoration of the out-of-service area. If not fully restored, go to the next step; otherwise, stop.

Step 3-5: Determine which loads should not be restored and execute the load shedding operation.

An overall flowchart of the proposed three-stage methodology is summarized in Fig. 2.

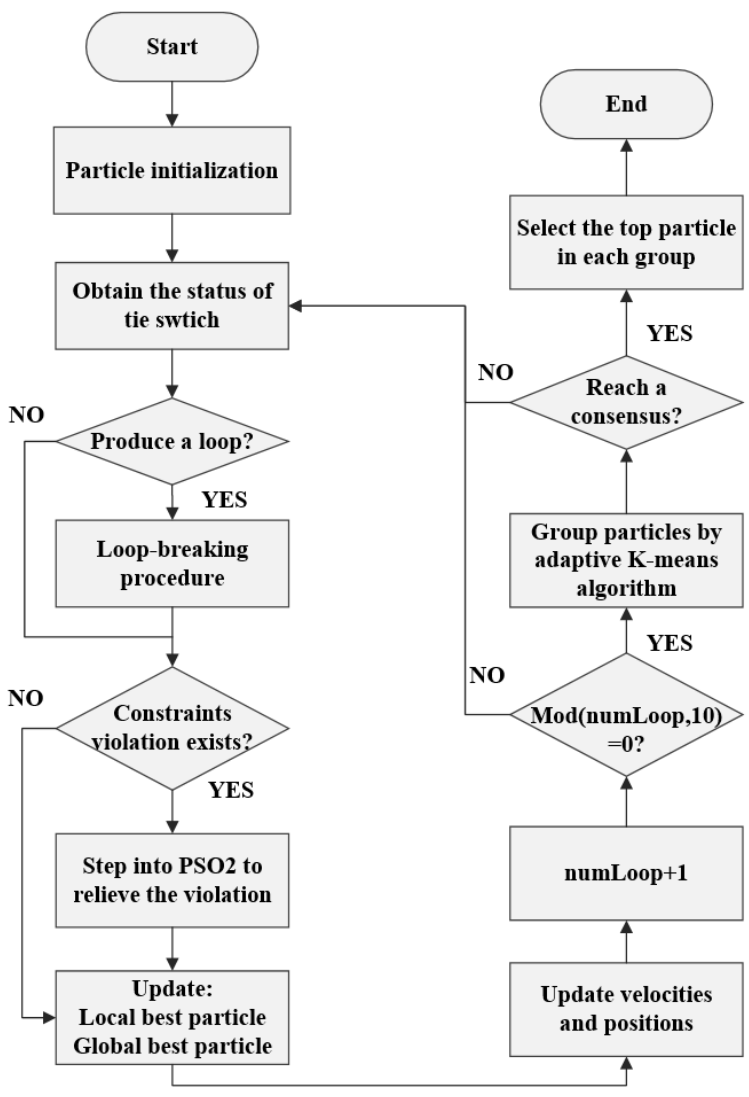

Fig. 3. The flowchart of the proposed group-based PSO algorithm.

\section{Computational Considerations}

This section provides a detailed description of the heuristic strategies incorporated in Stage I. These strategies are designed based on the characteristic of the service restoration problem to avoid a large number of meaningless solutions and to significantly reduce computation effort.

\section{A. Relieving Constraints Violation}

To avoid the so-called "curse of dimensionality" as the number of switches increases, we identify the "tie switch" and "sectionalizing switch" and differentiate switches in different tiers [19]. Correspondingly, the decision variables of PSO in Stage I are decomposed into two subpopulations: PSO1 and PSO2. Network configuration is determined by PSO1, whose purpose is to evolve the status of tie switches, ts. As described in Fig. 3, if a solution causes constraint violations (i.e., overloaded lines), we will step into the PSO2, whose objective is to remove the overload violation by evolving the status of the sectionalizing switches, ss. In both PSO1 and PSO2, each particle represents a part of the solution vector of the given problem, which form the status of all switches in the network. The dimension of each particle is equal to the number of $t s$ in population PSO1 and ss in PSO2. The switch status is a binary value, 0 or 1 , where 0 means an open switch and 1 means a closed switch.

\section{B. Maintaining a Radial Structure}

A key issue in system operation is maintaining the radial 


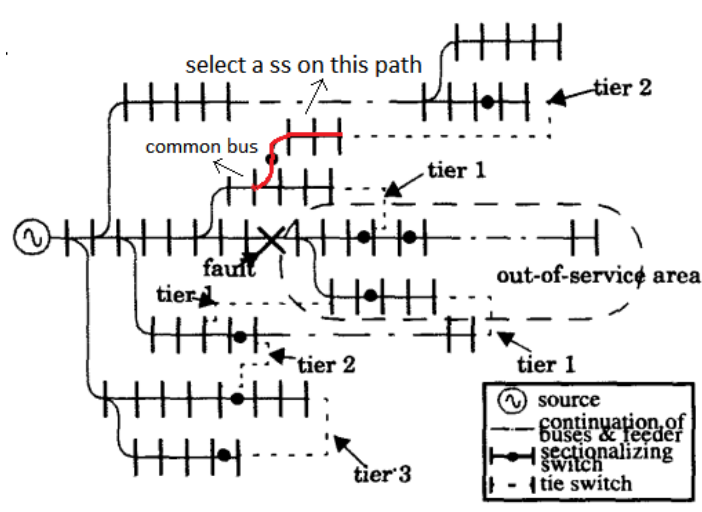

Fig. 4. A procedure for breaking a loop.

structure of the distribution networks. During the PSO iterative process, it is easy to create loops when a switch status changes from open to closed, breaking the constraint of radial structure. Therefore, a loop-breaking procedure is incorporated into the iteration process in Stage I. Several rules are employed in this procedure to break the loops and maintain the radial structure.

When a loop contains simply Tie 1 switches, we will randomly open a sectionalizing switch on the loop. When closing a tie switch in Tier 2 (or a higher tier) leads to a loop structure, selecting an more appropriate sectionalizing switch on the loop is more effective. As illustrated in Fig. 4, an ss lying on the path from the Tier 2 switch to its corresponding Tier 1 switch is preferred, since it not only can transfer load to Tier 2, but also maintain the radial structure and the level of recovery ratio.

It is noted that the islanding operation is an inevitable status during the intermediate process of group-based PSO. Actually, the emergence of "islanding" will be reflected by a low amount of load in service, the particles that lead to island operation have a low fitness value and thus will not be selected as high-quality solutions at the end of Stage I. Thus we don't use special techniques to avoid islanding in this paper.

\section{Test Results}

The IEEE 123-node test feeder (see Fig. 5) and a practical 1011-node distribution network are used to illustrate the effectiveness of the proposed multi-objective formulation and the proposed user-centered methodology. For the IEEE 123 -node test feeder, the total load of the system is $4930 \mathrm{kw}$ and

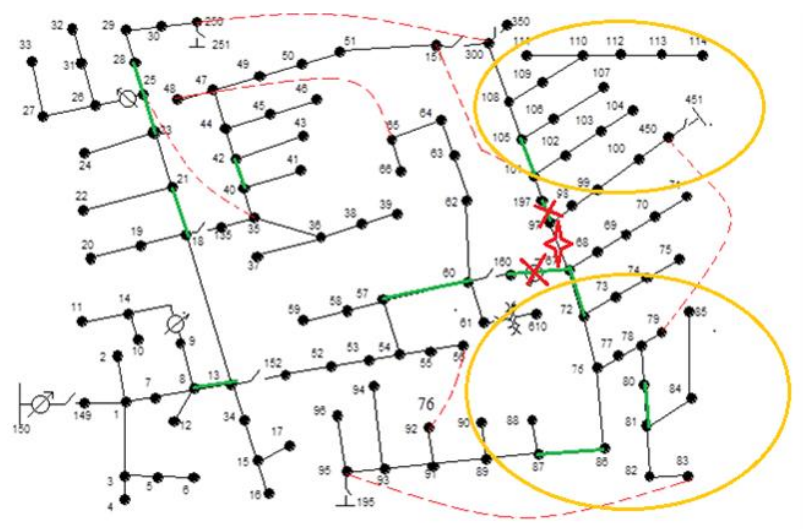

Fig. 5. The IEEE 123-node feeder test case.
TABLE II

123-NODE NETWORK COMPONENT LIST

\begin{tabular}{|c|c|}
\hline Component Type & \#of each \\
\hline Tie switches & 7 \\
\hline Sectionalizing switches & 15 \\
\hline Balanced loads & 4 \\
\hline Unbalanced loads & 81 \\
\hline
\end{tabular}

2970kvar. The system information is summarized in Table II. All of the transformers and lines immediately before or after a transformer are protected by circuit breakers. Faults occurring on these branches can be isolated by operating these devices. Faults on other branches are isolated by operating the upstream and downstream sectionalizing switches or breakers. The acceptable operating voltage range under emergency situations is $110 \mathrm{kv}-130 \mathrm{kv}$. The implicit Z-bus method is applied to calculate the unbalanced power flow in the distribution system [16]. The methodology is implemented by C-programming and a combinations of ZIP load model are considered in test cases.

Outputs of the proposed three-stage method are organized as follows:

(i) Total outage loads before and after service restoration for each fault;

(ii) Total number of switch operations required;

(iii) Candidate switches for each restoration scheme;

(iv) Un-restored loads and the index of restoration ratio, which is defined as the served loads divided by the total loads, expressed as follows.

$$
\text { Restoration ratio }=\frac{\text { served loads }}{\text { total loads }} * 100 \%
$$

\section{A. Partial Service Restoration Case}

It is possible that a full load restoration may not be achievable because of i) the limited number or placement of switches, ii) heavy loading conditions, and iii) the capacity of lines in the network. These limitations prevent the system from transferring power to the out-of-service loads via existing switches. In this situation, we aim to minimize the outage loads with an acceptable number of switch operations.

In addition, several local optimal restoration solutions may exist where the restoration ratios are similar but the required switch operations are different. Our methodology can provide multiple local optimal solutions with different numbers of required switch operations. One advantage of the proposed three-stage methodology is that it provides operators with multiple restoration schemes to choose a preferable one according to the operator preference. Tables III-V list a detailed solution procedure for a fault on line 13-18 to explain the proposed method. The population of particle swarms is set to 20 and the stop criterion is all of the particles achieving a consensus instead of the maximal iteration numbers.

Outputs from Stage I are summarized in Table III, which lists the total served load and the number of required switch operations of each solution. Stage I applies a clustering scheme to select high-quality solutions in each cluster with the thought that PSO may have stepped into a local search. The selected 
TABLE III

A Partial List of Multiple SOlutions ObTained From Stage I

\begin{tabular}{|c|c|c|c|c|}
\hline \multirow{2}{*}{ No. } & Solutions & Total Load & $\begin{array}{c}\text { \# of } \\
\text { Switch } \\
\text { Served }\end{array}$ & Ratio \\
\hline 1 & $\begin{array}{l}\text { open13-18, close56-48, } \\
\text { open 49-50 (group1) }\end{array}$ & $4840+\mathrm{j} 2915$ & 3 & $98.17 \%$ \\
\hline 2 & $\begin{array}{l}\text { open13-18,close300-151 } \\
\text { open101-105 (group2) }\end{array}$ & $3115+\mathrm{j} 1860$ & 3 & $63.04 \%$ \\
\hline 3 & $\begin{array}{l}\text { open13-18,close66-44, } \\
\text { open40-35 (group3) }\end{array}$ & $4250+\mathrm{j} 2540$ & 3 & $86.03 \%$ \\
\hline 4 & $\begin{array}{l}\text { open13-18,close56-48, } \\
\text { open72-76 (group1) }\end{array}$ & $4325+\mathrm{j} 2610$ & 3 & $87.77 \%$ \\
\hline 10 & $\begin{array}{l}\text { open13-18, close66-44, } \\
\text { open 101-105 (group3) }\end{array}$ & $4480+\mathrm{j} 2745$ & 3 & $91.29 \%$ \\
\hline 11 & $\begin{array}{l}\text { open13-18, close56-48, } \\
\text { open 67-97 (group1) }\end{array}$ & $4040+\mathrm{j} 2525$ & 3 & $82.78 \%$ \\
\hline 14 & $\begin{array}{l}\text { open13-18, close66-44, } \\
\text { open 101-105 (group3) }\end{array}$ & $4480+\mathrm{j} 2745$ & 3 & $91.29 \%$ \\
\hline 15 & $\begin{array}{l}\text { open13-18, close56-48, } \\
\text { open 60-160 (group1) }\end{array}$ & $3045+\mathrm{j} 1970$ & 3 & $63.01 \%$ \\
\hline 16 & $\begin{array}{l}\text { open13-18, close56-48, } \\
\text { open 54-94 (group1) }\end{array}$ & $4430+\mathrm{j} 2710$ & 3 & $90.23 \%$ \\
\hline
\end{tabular}

TABLE IV

TABLE OF USER-PREFERRED SOLUTIONS FROM STAGE II

\begin{tabular}{|c|l|c|c|c|}
\hline \multirow{2}{*}{ No. } & $\begin{array}{c}\text { User-Preferred } \\
\text { Solutions }\end{array}$ & $\begin{array}{c}\text { Total Load } \\
\text { Served }\end{array}$ & $\begin{array}{c}\text { \#of } \\
\text { Switc } \\
\text { h ops }\end{array}$ & \multirow{2}{*}{ Ratio } \\
\hline 1 & $\begin{array}{l}\text { open13-18, close56-48, } \\
\text { open 49-50 }\end{array}$ & $4840+\mathrm{j} 2915$ & 3 & $98.17 \%$ \\
\hline 8 & $\begin{array}{l}\text { open13-18, close56-48, } \\
\text { open 101-105 }\end{array}$ & $4480+\mathrm{j} 2745$ & 3 & $91.29 \%$ \\
\hline 10,14 & $\begin{array}{l}\text { open13-18, close66-44, } \\
\text { open 101-105 }\end{array}$ & $4480+\mathrm{j} 2745$ & 3 & $91.29 \%$ \\
\hline 6,18 & $\begin{array}{l}\text { open13-18, close66-44, } \\
\text { open 135-18 }\end{array}$ & $4410+\mathrm{j} 2640$ & 3 & $89.30 \%$ \\
\hline
\end{tabular}

solutions form the user preference table (Table IV). In stage II, operators can choose their preferable solutions for further improvement, which will be performed in Stage III.

Stage II: User Engagement: It's assumed that the user chooses the first objective as the primary and the value of $\varepsilon$ is set to 5. According to the $\varepsilon$-constraint method, the problem formulation can be rewritten as:

$$
\max _{g_{k} \in G_{R}} f_{1}=\sum_{k \in N_{R}}\left|\mathrm{P}_{L, k}\right|
$$

Subject to:

$$
\begin{gathered}
f_{1}(\mathrm{x}) \geq f_{1}\left(\mathrm{x}^{*}\right) \\
n_{\text {ops }} \leq 5 \\
f\left(V, g_{k}\right)=0 \\
P_{l}^{2}+Q_{l}^{2} \leq\left(S_{l}^{\max }\right)^{2} \quad \forall l \in F \\
V_{k}^{\min } \leq\left|V_{k}^{p}\right| \leq V_{k}^{\max } \quad \forall k \in N, p \in a, b, c \\
I_{k}^{\min } \leq\left|I_{k}^{p}\right| \leq I_{k}^{\max } \quad \forall k \in N
\end{gathered}
$$

Table $\mathrm{V}$ lists the further improved restoration solutions obtained in Stage III. It can be observed that when an appropriate value of $\varepsilon$ is chosen, better solutions can be provided in the third stage. However, when the $\varepsilon$ is set to other values smaller than 5 , we cannot find other feasible solutions.
TABLE V

SOLUTIONS OBTAINED FROM STAGE III (LOCAL STAGE)

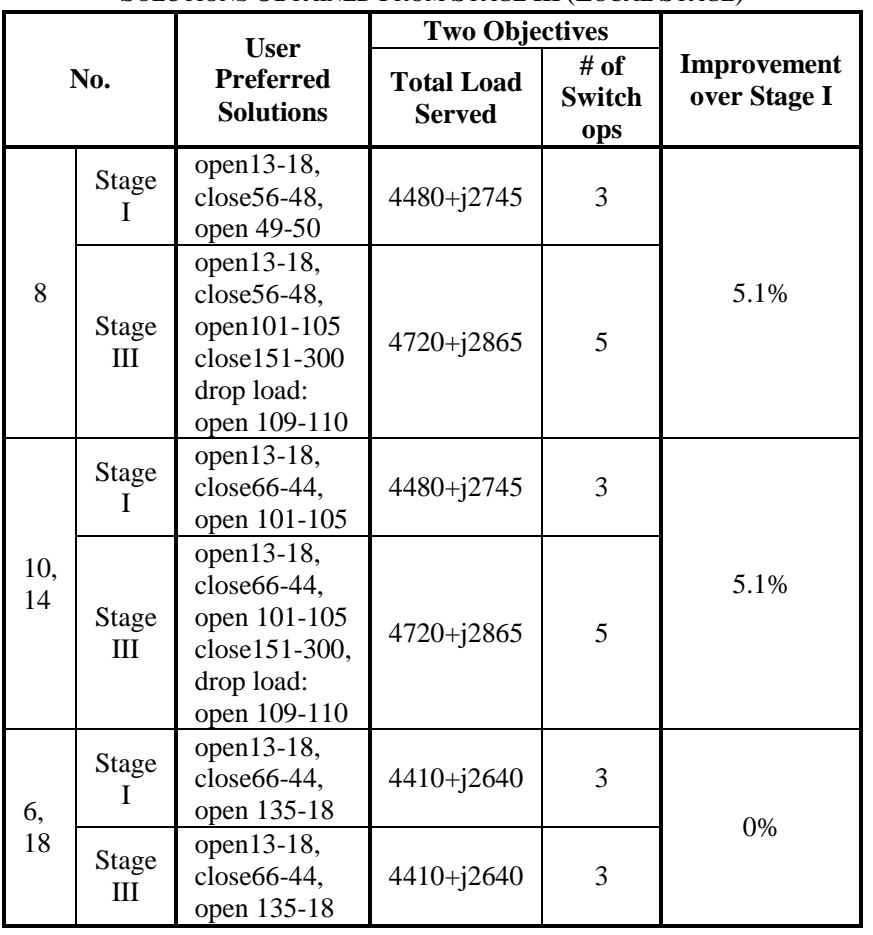

TABLE VII

User Preference Table Generated by K-MEans Clustering Method

\begin{tabular}{|c|c|c|c|c|}
\hline Cluster & Switch operation & $\begin{array}{c}\text { Loss } \\
(\mathrm{kw}, \mathrm{kvar})\end{array}$ & $\begin{array}{c}\text { Swi } \\
\text { No. }\end{array}$ & Ratio \\
\hline 1 & $\begin{array}{c}\text { Close 116(17) } \\
\text { Open 118,119 }\end{array}$ & $\begin{array}{c}70.13 \\
119.47\end{array}$ & 3 & $94.27 \%$ \\
\hline 2 & $\begin{array}{c}\text { Close116,125(10) } \\
\text { Open 119,127 }\end{array}$ & $\begin{array}{c}75.64 \\
130.74\end{array}$ & 4 & $100 \%$ \\
\hline 3 & $\begin{array}{c}\text { Close 113,116 } \\
\text { Open 51,119(2) }\end{array}$ & $\begin{array}{c}75.29 \\
129.79\end{array}$ & 4 & $100 \%$ \\
\hline 4 & $\begin{array}{c}\text { Close 113,116 } \\
\text { Open119,131 (4,5,15) }\end{array}$ & $\begin{array}{c}75.29 \\
129.79\end{array}$ & 4 & $100 \%$ \\
\hline
\end{tabular}

TABLE VIII

IMPROVEMENT IN LOCAL SEARCH STAGE

\begin{tabular}{|c|c|c|c|c|}
\hline Method & Switch operation & $\begin{array}{c}\text { Loss } \\
(\mathrm{kw}, \mathrm{kvar})\end{array}$ & $\begin{array}{c}\text { Swi } \\
\text { No. }\end{array}$ & Ratio \\
\hline $\begin{array}{c}\text { PSO alone } \\
\text { (Cluster 1) }\end{array}$ & $\begin{array}{c}\text { Close 125 } \\
\text { Open 51,119 }\end{array}$ & $\begin{array}{c}94.75 \\
169.85\end{array}$ & 3 & $98.43 \%$ \\
\hline $\begin{array}{c}\text { Proposed } \\
\text { method }\end{array}$ & $\begin{array}{c}\text { Close 125,113 } \\
\text { Open 51,119 }\end{array}$ & $\begin{array}{c}98.12 \\
176.77\end{array}$ & 4 & $100 \%$ \\
\hline $\begin{array}{c}\text { PSO alone } \\
\text { (Cluster 2) }\end{array}$ & $\begin{array}{c}\text { Close 116 } \\
\text { Open 118,119 }\end{array}$ & $\begin{array}{c}70.13 \\
119.47\end{array}$ & 3 & $94.27 \%$ \\
\hline $\begin{array}{c}\text { Proposed } \\
\text { method }\end{array}$ & $\begin{array}{c}\text { Close 116,125 } \\
\text { Open 118,119 }\end{array}$ & $\begin{array}{c}98.12 \\
176.77\end{array}$ & 4 & $100 \%$ \\
\hline $\begin{array}{c}\text { PSO alone } \\
\text { (Cluster 3) }\end{array}$ & $\begin{array}{c}\text { Close 116 } \\
\text { Open 119,127 }\end{array}$ & $\begin{array}{c}68.58 \\
116.41\end{array}$ & 3 & $94.27 \%$ \\
\hline $\begin{array}{c}\text { Proposed } \\
\text { method }\end{array}$ & $\begin{array}{c}\text { Close 116,125 } \\
\text { Open 119,127 }\end{array}$ & $\begin{array}{c}76.63 \\
133.01\end{array}$ & 4 & $100 \%$ \\
\hline $\begin{array}{c}\text { PSO alone } \\
\text { (Cluster 4) }\end{array}$ & $\begin{array}{c}\text { Close 113 } \\
\text { Open 118,119 }\end{array}$ & $\begin{array}{c}84.98 \\
149.28\end{array}$ & 3 & $94.27 \%$ \\
\hline $\begin{array}{c}\text { Proposed } \\
\text { method }\end{array}$ & $\begin{array}{c}\text { Close 113,115 } \\
\text { Open 118,119 }\end{array}$ & $\begin{array}{c}96.65 \\
173.34\end{array}$ & 4 & $100 \%$ \\
\hline
\end{tabular}

The effectiveness of Stage III is reflected by the improvements achieved.

\section{B. Complete Service Restoration Case}

This section shows the excellent search performance of the proposed method in terms of solution diversity, which provides viable alternatives for service restoration. We study a fault on 
TABLE VI

SOLUTIONS OBTAINED FROM STAGE I ON FAULT 160-67 AT HEAVY-LOADED CONDITIONS

\begin{tabular}{|c|c|c|c|c|c|c|c|c|c|}
\hline No. & Switch operation & $\begin{array}{c}\text { Loss } \\
\text { (kw, kvar) }\end{array}$ & $\begin{array}{l}\text { Swi } \\
\text { No. }\end{array}$ & ratio & No. & Switch operation & Loss & $\begin{array}{l}\text { Swi } \\
\text { No. }\end{array}$ & ratio \\
\hline 1 & $\begin{array}{l}\text { Close113,116,125,130 } \\
\text { Open51,119,126,131 }\end{array}$ & $\begin{array}{c}75.37 \\
130.15\end{array}$ & 8 & $100 \%$ & 11 & $\begin{array}{l}\text { Close } 125 \\
\text { Open } 51,119\end{array}$ & $\begin{array}{l}94.75 \\
169.85\end{array}$ & 3 & $98.43 \%$ \\
\hline 2 & $\begin{array}{l}\text { Close } 113,116 \\
\text { Open } 51,119\end{array}$ & $\begin{array}{c}75.29 \\
129.79\end{array}$ & 4 & $100 \%$ & 12 & $\begin{array}{l}\text { Close } 113 \\
\text { Open } 119,127\end{array}$ & $\begin{array}{c}84.07 \\
147.61\end{array}$ & 3 & $94.27 \%$ \\
\hline 3 & $\begin{array}{l}\text { Close } 116 \\
\text { Open } 119,127\end{array}$ & $\begin{array}{c}68.58 \\
116.41\end{array}$ & 3 & $94.27 \%$ & 13 & $\begin{array}{l}\text { Close } 113,116 \\
\text { Open } 51,119,131\end{array}$ & $\begin{array}{c}75.29 \\
129.79\end{array}$ & 5 & $100 \%$ \\
\hline 4 & $\begin{array}{l}\text { Close } 113,116 \\
\text { Open119,131 }\end{array}$ & $\begin{array}{c}75.29 \\
129.79\end{array}$ & 4 & $94.27 \%$ & 14 & $\begin{array}{l}\text { Close } 113 \\
\text { Open } 118,119\end{array}$ & $\begin{array}{c}84.98 \\
149.28\end{array}$ & 3 & $94.27 \%$ \\
\hline 5 & $\begin{array}{l}\text { Close } 113,116 \\
\text { Open } 119,131\end{array}$ & $\begin{array}{c}75.29 \\
129.79\end{array}$ & 4 & $94.27 \%$ & 15 & $\begin{array}{l}\text { Close } 113,116 \\
\text { Open } 119,131\end{array}$ & $\begin{array}{c}75.29 \\
129.79\end{array}$ & 4 & $100 \%$ \\
\hline 6 & $\begin{array}{l}\text { Close } 116 \\
\text { Open 51,119 }\end{array}$ & $\begin{array}{c}75.19 \\
130.04\end{array}$ & 3 & $98.43 \%$ & 16 & $\begin{array}{l}\text { Close } 116 \\
\text { Open119.128 }\end{array}$ & $\begin{array}{c}65.54 \\
110.19\end{array}$ & 3 & $91.67 \%$ \\
\hline 7 & $\begin{array}{l}\text { Close } 125 \\
\text { Open } 51,119\end{array}$ & $\begin{array}{l}94.75 \\
169.85\end{array}$ & 3 & $98.43 \%$ & 17 & $\begin{array}{l}\text { Close } 116 \\
\text { Open } 118,119\end{array}$ & $\begin{array}{c}70.13 \\
119.47\end{array}$ & 3 & $94.27 \%$ \\
\hline 8 & $\begin{array}{l}\text { Close } 116 \\
\text { Open } 51,119\end{array}$ & $\begin{array}{c}75.19 \\
130.04\end{array}$ & 3 & $98.43 \%$ & 18 & $\begin{array}{l}\text { Close } 125 \\
\text { Open 51,119 }\end{array}$ & $\begin{array}{c}94.75 \\
169.85\end{array}$ & 3 & $98.43 \%$ \\
\hline 9 & $\begin{array}{l}\text { Close } 116 \\
\text { Open } 51,119\end{array}$ & $\begin{array}{c}75.19 \\
130.04\end{array}$ & 3 & $98.43 \%$ & 19 & $\begin{array}{l}\text { Close } 116 \\
\text { Open119.128 }\end{array}$ & $\begin{array}{c}65.54 \\
110.19\end{array}$ & 3 & $91.67 \%$ \\
\hline 10 & $\begin{array}{l}\text { Close } 116,125 \\
\text { Open } 119,127\end{array}$ & $\begin{array}{c}75.64 \\
130.74\end{array}$ & 4 & $100 \%$ & 20 & $\begin{array}{l}\text { Close } 113 \\
\text { Open } 118,119\end{array}$ & $\begin{array}{c}84.98 \\
149.28\end{array}$ & 3 & $94.27 \%$ \\
\hline
\end{tabular}

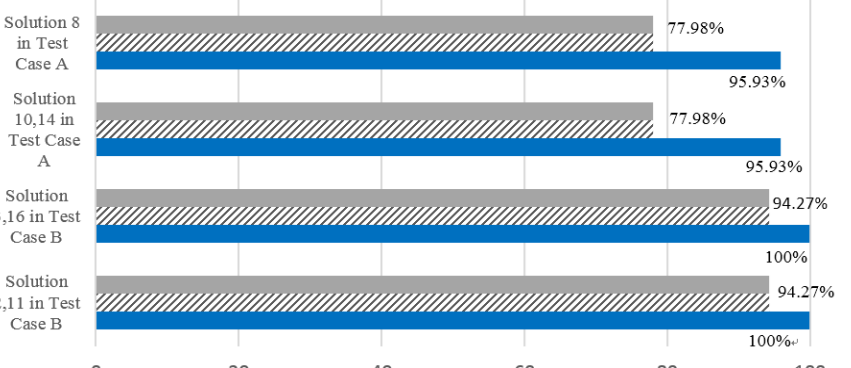

Fig. 6. Improvement in the restoration ratio achieved by each stage of the three-stage methodology.

TABLE IX

COMPARISON RESUlts BETWEEN THE PROPOSED METHOD AND A LoCAL METHOD ON FAUlt 57-60. THE PROPOSED METHOD OUTPERFORMS LOCAL METHODS

\begin{tabular}{|c|c|c|c|c|c|}
\hline \multirow[b]{2}{*}{ Method } & \multicolumn{2}{|c|}{ Outage Load (kw, kvar) } & \multicolumn{2}{|c|}{ Two Objectives } & \multirow[b]{2}{*}{$\begin{array}{l}\text { Improv } \\
\text { ement }\end{array}$} \\
\hline & $\begin{array}{c}\text { Outage } \\
\text { load }\end{array}$ & $\begin{array}{c}\text { Restored } \\
\text { load }\end{array}$ & $\begin{array}{c}\text { \# of } \\
\text { switch } \\
\text { ops }\end{array}$ & $\begin{array}{c}\text { Ratio of } \\
\text { Restored } \\
\text { Load } \\
\end{array}$ & \\
\hline $\begin{array}{c}\text { Proposed } \\
\text { method }\end{array}$ & $1885+\mathrm{j} 1000$ & $1885+\mathrm{j} 1000$ & 3 & $100 \%$ & \multirow{2}{*}{$6.5 \%$} \\
\hline $\begin{array}{c}\text { method } \\
\text { in [16] }\end{array}$ & $1885+\mathrm{j} 1000$ & $1780+\mathrm{j} 920$ & 2 & $93.90 \%$ & \\
\hline
\end{tabular}

TABLE X

A COMPARISON TABLE ON FAULT 13-18 SHOWING THAT THE PROPOSED METHOD OUTPERFORMS LOCAL METHODS.

\begin{tabular}{|c|c|c|c|c|c|}
\hline \multirow[b]{2}{*}{ Method } & \multicolumn{2}{|c|}{ Outage Load ( $\left.\mathbf{I}_{\text {load }}\right)$} & \multicolumn{2}{|c|}{ Two Objectives } & \multirow[b]{2}{*}{ Improvement } \\
\hline & $\begin{array}{c}\text { Outage } \\
\text { load }\end{array}$ & $\begin{array}{c}\text { Restored } \\
\text { load }\end{array}$ & $\begin{array}{c}\text { \# of } \\
\text { switch } \\
\text { ops }\end{array}$ & $\begin{array}{c}\text { Ratio of } \\
\text { Restored } \\
\text { Load }\end{array}$ & \\
\hline $\begin{array}{c}\text { Proposed } \\
\text { method }\end{array}$ & 963.66 & 859.06 & 2 & $89.15 \%$ & \multirow{2}{*}{$9.58 \%$} \\
\hline $\begin{array}{c}\text { method } \\
\text { in [16] }\end{array}$ & 963.66 & 783.92 & 5 & $81.35 \%$ & \\
\hline
\end{tabular}

line 160-67 with outage loads $75.29 \mathrm{kw}+\mathrm{j} 119.79 \mathrm{kvar}$. In Stage I, the group-based PSO generates a set of feasible solutions located in several promising sub-regions in the search space (Table VI). It generates five fully-restored solutions with different real and reactive power losses. To find more restoration schemes with 100 percent load restoration, Table VII shows the best solutions in each cluster separated by the adaptive K-means clustering method. Switch operation, total power loss, and the restoration ratio of each solution are listed in this table to provide a reference for the operators. In Stage III, these promising solutions are improved by the local search method.

It can be observed in Table VIII that we are able to find three new high-quality solutions in the sub-region around the selected solution. It is demonstrated in this case that this methodology is efficient in exploiting diversified high-quality solutions and takes less computational efforts compared with traditional PSOs. The proposed methodology offers users more flexible choices. The improvement in the restoration ratio achieved by each stage of the proposed methodology is summarized in Fig. 6.

\section{A Comparison Study}

To evaluate the performance of the proposed method in terms of solution quality, a comparison is made between the method in [20] and the proposed three-stage restoration method. This comparison highlights significant improvements made by the proposed method, which can be seen in Table IX$\mathrm{X}$ with the following two improvements observed:

- A significant increase in the total load restored;

- A reduction in the required number of switch operations.

Note that both of the objective functions are indeed improved while the switch operations desired by the user are accommodated. Compared with the heuristic method proposed in [20], we notice that the proposed method can find better solutions. On the other hand, compared with the traditional PSO method, the proposed method is both faster and more effective. Because of its "knowledge" of feasible solutions, it avoids a large number of infeasible solutions and thus requires fewer iterations during the search procedure. 


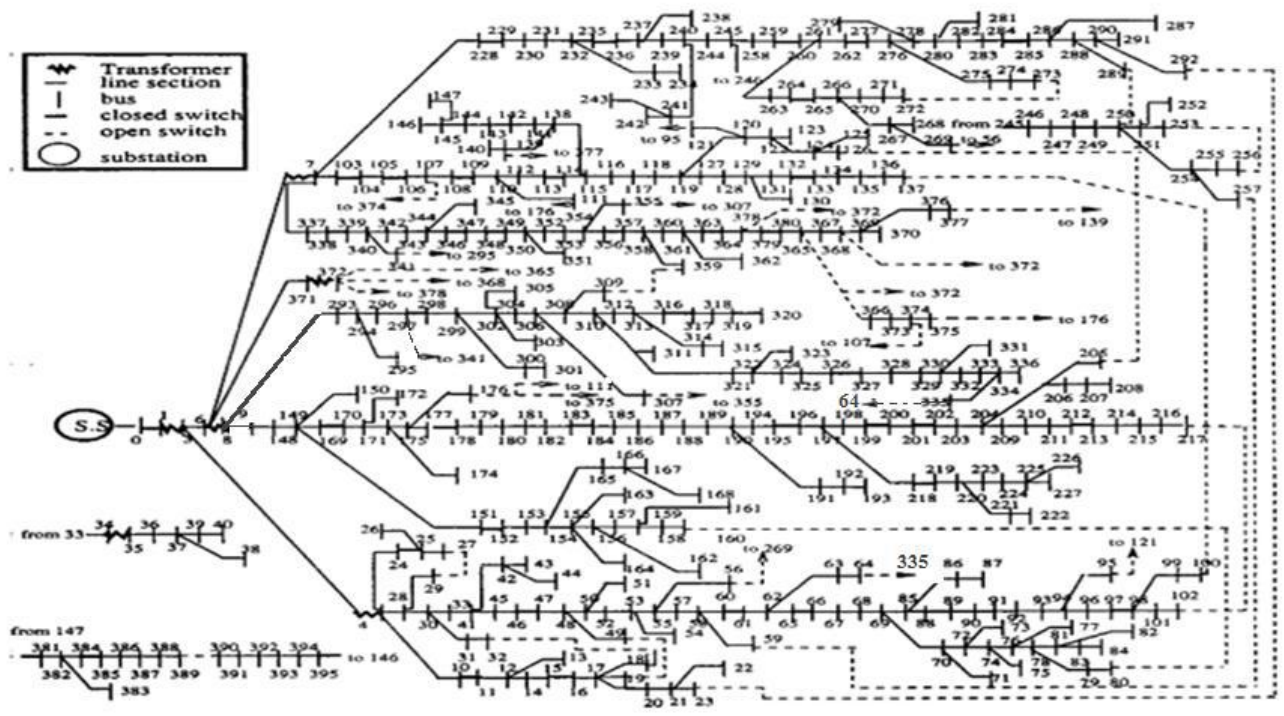

Fig. 7. A one-line diagram of the 394 bus, 1101 node test system.

TABLE XI 1101-NODE NETWORK COMPONENT LIST

\begin{tabular}{|c|c|}
\hline Component Type & \# of each \\
\hline \# of lines & 343 \\
\hline \# of transformers & 7 \\
\hline Load condition (total) & $26.03 \mathrm{MW}, 13.48 \mathrm{MVar}$ \\
\hline \# of tie switches & 27 \\
\hline \# of sectionalizing switches & 46 \\
\hline
\end{tabular}

TABLE XII

SOLUTIONS OBTAINED IN GROUP-BASED PSO ON FAULT 297-298

\begin{tabular}{|c|c|c|c|c|}
\hline \multirow[b]{2}{*}{ No. } & \multirow{2}{*}{$\begin{array}{c}\text { User- } \\
\text { Preferred } \\
\text { Solutions }\end{array}$} & \multicolumn{2}{|c|}{ Two Objectives } & \multirow[b]{2}{*}{ Ratio } \\
\hline & & Load Served & $\begin{array}{c}\text { \# of } \\
\text { switch } \\
\text { ops }\end{array}$ & \\
\hline $2,5,7$ & $\begin{array}{c}\text { open } \\
\text { 296-297, } \\
\text { open } \\
298-299 \\
\text { close } 64-335\end{array}$ & $2628655+\mathrm{j} 1369295$ & 3 & $99.97 \%$ \\
\hline 14 & $\begin{array}{c}\text { open } \\
296-297, \\
\text { open } \\
298-299, \\
\text { close } \\
355-307 \\
\end{array}$ & $2628655+\mathrm{j} 1369295$ & 3 & $99.97 \%$ \\
\hline 15,8 & $\begin{array}{c}\text { open } \\
296-297, \\
\text { open } \\
298-299, \\
\text { close } \\
359-309\end{array}$ & $2628655+\mathrm{j} 1369295$ & 3 & $99.97 \%$ \\
\hline 4,10 & $\begin{array}{c}\text { open } \\
\text { 296-297, } \\
\text { open } \\
298-299 \\
\text { close341-297 } \\
\end{array}$ & $2145226+\mathrm{j} 1134749$ & 3 & $81.86 \%$ \\
\hline
\end{tabular}

D. 1101-node practical system

The proposed three-stage method is also evaluated on a 394-bus, 1101 node practical unbalanced network (see Fig. 7). Detailed information about the network is displayed in Table $\mathrm{XI}$. The acceptable voltage range used is $110 \mathrm{kV}-130 \mathrm{kV}$. When a fault occurs on line 297-298, Stage I generates multiple solutions to restore the out-of-service load. Table XII shows the top particles obtained by the group-based PSO method in Stage I. It is observed that three different high-quality solutions are found in this stage.

We select the solution with an $81.86 \%$ restoration ratio for further improvement. We apply the rank-based local method with the selected solution as initial condition. It converges to a near fully restored solution which is the same as particle 14. It indicates that particle 14 is the local optimal solution in the neighborhood of the selected one. This study illustrates that multiple high-quality solutions can be obtained by the proposed method.

TABLE XIII

SOLUTIONS OBTAINED BY STAGE III: LOCAL STAGE

\begin{tabular}{|c|c|c|c|c|c|}
\hline \multirow{2}{*}{\multicolumn{2}{|c|}{ Solution }} & \multirow{3}{*}{$\begin{array}{l}\begin{array}{c}\text { User- } \\
\text { Preferred } \\
\text { Solutions }\end{array} \\
\text { open } \\
296-297, \\
\text { open } \\
298-299, \\
\text { close341-297 }\end{array}$} & \multicolumn{2}{|c|}{ Two Objectives } & \multirow[b]{2}{*}{ Improvement } \\
\hline & & & Land Sarved & \# of & \\
\hline \multirow{2}{*}{8} & $\begin{array}{l}\text { Stage } \\
\text { I\&II }\end{array}$ & & $2145226+\mathrm{j} 1134749$ & 3 & \multirow{2}{*}{$22.1 \%$} \\
\hline & $\begin{array}{c}\text { Stage } \\
\text { III }\end{array}$ & $\begin{array}{l}\text { open } \\
296-297, \\
\text { open } \\
298-299, \\
\text { close355-307 }\end{array}$ & $2628655+\mathrm{j} 1369295$ & 3 & \\
\hline
\end{tabular}

\section{CONCLUSION}

We present a multi-objective problem formulation and develop a three-stage methodology tailored to user-centered service restoration with the following two goals: (i) restoring more customer loads with (ii) fewer switch operations. Stage I is designed to generate a set of near optimal solutions located in several promising sub-regions in the search space. Stage III locates the corresponding local optimal solution of the selected 
solution by users. The proposed three-stage methodology offers several distinguishing features such as (i) engagement of operators in decision-making, (ii) diverse and high-quality solutions satisfying users preferences, (iii) efficient searching, and (iv) suitable for large-scale network applications. In addition, the adaptive K-means clustering scheme can assist users in facilitating their choices. The numerical studies and comparison results reveal that this method can provide flexible restoration scheme for practical systems.

\section{ACKNOWLEDGEMENT}

This work was supported by the U.S. National Science Foundation (NSF) under Award 1225682.

\section{REFERENCES}

[1] Y.-S. Ko, "An Inference Methodology Based on the Local Minimum Tree Search to Solve the Distribution System Events Under Heavy Load Condition", IEEE Trans. Power Delivery, vol. 27, pp. 725-734, Apr. 2012.

[2] S. Filipiak, "Application of evolutionary algorithm in optimization of medium-voltage distribution networks post-fault configuration", International Journal of Electrical Power \& Energy Systems, 2013; vol. 44(1):666-671

[3] S. P. Singh, G. S. Raju, G. K. Rao, M. Afsari, "A heuristic method for feeder reconfiguration and service restoration in distribution networks", International Journal of Electrical Power \& Energy Systems, 2009; vol. 31(7-8):309-314.

[4] F. V. Gomes, S. Jr. Carneiro, J. L. R. Pereira, M. P. Vinagre, P. N. A. Garcia, and L.R. Araujo, "A new heuristic reconfiguration algorithm for large distribution systems", IEEE Trans. Power Systems, vol. 20, pp. 1373-1378, Aug. 2005.

[5] E. José de Oliveira, G. José Rosseti, L. Willer de Oliveira, F. Vanderson Gomes, W. Peres, "New algorithm for reconfiguration and operating procedures in electric distribution systems", International Journal of Electrical Power \& Energy Systems, 2014; vol. 57:129-134.

[6] M.-S. Tsai, "Development of an Object-Oriented Service Restoration Expert System with Load Variations," IEEE Trans. Power Systems, vol. 23, pp. 219-225, Feb. 2008.

[7] K. Kuroda, Y. Takegoshi, K. Yamashita, M. Ito, S. Fukui, "Verification of a knowledge-based restoration guidance system in a local dispatching center," International Journal of Electrical Power \& Energy Systems, 1993; vol. 15(3):185-192.

[8] H. M. Khodr, J. Martínez-Crespo, M. A. Matos, J. Pereira, "Distribution Systems Reconfiguration Based on OPF Using Benders Decomposition", IEEE Trans. Power Delivery, vol. 24, pp. 2166-2176, Oct. 2009.

[9] C.-M. Huang, C.-T. Hsieh, Y.-S. Wang, "Evolution of radial basic function neural network for fast restoration of distribution systems with load variations," International Journal of Electrical Power \& Energy Systems, 2011; vol. 33(4):961-968.

[10] K. Sathish Kumar, T. Jayabarathi, "Power system reconfiguration and loss minimization for a distribution systems using bacterial foraging optimization algorithm", International Journal of Electrical Power \& Energy Systems, 2012; vol. 36(1):13-17.

[11] J. Stępień, S. Filipiak, Application of the evolutionary algorithm with memory at the population level for restoration service of electric power distribution networks," International Journal of Electrical Power \& Energy Systems, 2014; vol. 63, Dec., pp. 695-704

[12] H.-T. Yang, C.-M. Huang, J. Kennedy, R. Eberhard, "Distribution system service restoration using fuzzy Petri Net models", International Journal of Electrical Power \& Energy Systems, vol. 24, pp. 395-403, Jun. 2002.

[13] A. Augugliaro, L. Dusonchet, E. Riva Sanseverino, "Multiobjective service restoration in distribution networks using an evolutionary approach and fuzzy sets," International Journal of Electrical Power \& Energy Systems, 2000; vol. 22:103-110.

[14] R. M. Ciric, D. S. Popovic, "Multi-objective distribution network restoration using heuristic approach and mix integer programming method", International Journal of Electrical Power \& Energy Systems, 2000; vol. 22(7):497-505.
[15] B. Amanulla, S. Chakrabarti, S. N. Singh, "Comparative study of modern heuristic algorithms to service restoration in distribution systems", IEEE Trans. Power Delivery, vol. 27, pp.918-926, Apr. 2002.

[16] T. H. Chen, M. S. Chen, K. J. Hwang, P. Kotas, and E. A. Chebi, "Distribution system power flow analysis-a rigid approach", IEEE Trans. Power Delivery, vol. 6, no. 3, pp. 1146-1152, Jul. 1991.

[17] W.-Y. Yu, V.-W. Soo, M.-S. Tsai, Y.-B. Peng, "Coordinating a society of switch agents for power distribution service restoration in a smart grid," The 16th International Conference on Intelligent System Application to Power Systems (ISAP), Sep. 2011.

[18] Jungsuk Kwac, June Flora, Ram Rajagopal, "Household Energy Consumption Segmentation using Hourly Data, " IEEE Transactions on Smart Grid, vol. 5, pp. 420-430. Jan. 2014.

[19] J. Kennedy, R. Eberhard, "Swarm Intelligence", Morgan Kaufmann Publishers, 2001.

[20] K. N. Miu, H.-D. Chiang, and R. J. McNulty, "Multi-tier service restoration through network reconfiguration and capacitor control for large scale radial distribution system", IEEE Trans. Power Systems, vol. 15, pp. 1001-1007, Apr. 2000.

[21] M. Kleinberg, K. Miu, and H.-D. Chiang, "Improving service restoration of power distribution systems through load curtailment of in-service customers", IEEE Trans. Power Systems, vol. 26, pp. 1110-1117, Aug. 2011.

Shuo Wang received the B.S. degree in electrical engineering from Tianjin University, Tianjin, China, in 2012. She is currently pursuing the doctoral degree in electrical engineering, School of Electrical Engineering and Automation, Tianjin University, Tianjin, China. Her technical interests include distribution system analysis, nonlinear dynamical systems, and optimization techniques applied to power systems.

Hsiao-Dong Chiang (M'87-SM'91-F'97) received the Ph.D. degree in electrical engineering and computer science from the University of California, Berkeley, in 1986. He is currently a professor of electrical and computer engineering at Cornell University, Ithaca, NY. He holds 17 U.S. patents related to power systems and Trust-Tech-based nonlinear optimization techniques. His research and development interests include theoretical development and practical applications of nonlinear system theory, computation, and application to electrical circuits, systems, signals, and images. He authored two books: Direct Methods for Stability Analysis of Electric Power Systems: Theoretical Foundation, BCU Methodologies, and Applications (New York: Wiley/IEEE Press, 2011) and Stability Region of Nonlinear Dynamical System: Theory, Optimal Estimation and Applications (Cambridge: Cambridge University Press, 2015). 